\title{
EDITORIAL OFFICE CHANGES
}

B eginning with this issue of Ecological Restoration, the Editorial Office has moved from the University of Wisconsin to Rutgers, The State University of New Jersey. It is housed in the Department of Ecology, Evolution, and Natural Resources of the School of Environmental and Biological Sciences.

The new Editor is Steven N. Handel. He has explored pollination, seed dispersal, plant population patterns, and most recently, problems of restoring urban and heavily degraded lands. He serves as professor of ecology and evolution at Rutgers University. Dr. Handel is an Aldo Leopold Leadership Fellow and Certified Senior Ecologist of the Ecological Society of America, a Fellow of the American Association for the Advancement of Science, and an Honorary Member of the American Society of Landscape Architects. Prior to being at Rutgers, he was Associate Professor of Biology and Director of the Marsh
Botanical Garden at Yale University. He is a member of the State of New Jersey Invasive Species Council and participates in ecological restoration designs in new public parks throughout the country. He received a B. A. in Biology at Columbia College, and a Ph.D. from the Field of Ecology and Evolution at Cornell University.

The new Managing Editor is Brooke Maslo. She has a research background in restoring and enhancing wildlife habitats, with a focus on threatened and endangered coastal birds. She has worked for the New Jersey Division of Fish and Wildlife Endangered and Nongame Species Program and has designed ecological restoration protocols for public parks. In addition to her restoration activities, she has taught at the university level in restoration ecology, animal behavior, and wildlife conservation. She received a B. S. in Engineering from the University of Maryland and a Ph.D. in Ecology and Evolution from Rutgers University. 